\title{
TRADICIJA I INOVACIJA - DVE STRANE DIGITALNE HUMANISTIKE
}

\begin{abstract}
Sažetak
Rad se bavi analizom diskursa koji se odnose na inovativnost I tradiciju u oblasti digitalne humanistike. Dok jedni ističu kvantitaivne apskete drugi ukazuju na kvalitativni skok koji novi medij unosi u humanističke discipline I profesiju.
\end{abstract}

Ključne reči: tradicija, inovacija, obrazovanje, digitalizacija, humanistika

Diskurs o digitalnoj humanistici. U mnogim napisima i studijama u protekle (sada već) nekolike decenije nalazimo gotovo istovetne iskaze o sasvim novom tehnološkom, ubrzanom dobu digitalizacije. Međutim nije jasno uvek na šta se konkretno misli: novim stvaralačkim ili praktičnim pristupima, novim saznanjima ili bržem širenju tradicionalnog znanja, novim metodama ili samo novim tehnikama. Tako dok neki tvrde da se epistemološka i ontološka osnova našeg znanja menjaju, da nam je potrebna nova filozofija, drugi razmatraju praktične upotrebe koje revolucionarizuju stare poslove kao što su stvaranje bibliotečkih kataloga, bibliografskih baza, elektronsku poštu koja je zamenila stari način dopisivanja, dostupnost elektronskih verzija tekstova (književnih i neknjiževnih), ili uopšte dostupnost informacija raznog tipa preko pretražvača poput Google-a, i sl.

U prvom periodu digitalne humanistike smatralo se da je glavni cilj da se tradicionalni humanistički tekstovi (u najširem smislu te reči) pretvore u takav oblik da se mogu kompjuterskim softverom obraditi, stvarajući baze podataka, digitalne arhive i tagirane tekstove. U post-digitalnoj humanistici, a to je već drugi, naš, savremeniji period, kompjuterizacija je u toj meri obuhvatila naš svet i kulturu, da se može govoriti o načinima na koje se „kultura materijalizuje [...] kroz tehnička sredstva, sisteme beleženja 
(snimanja), [...] i sve sa gigantskim bazama podataka" o važnim i manje važnim stvarima, te je došlo vreme preispitivanja. (David Berry, 2014)

$\mathrm{U}$ interesantnom radu posvećenom "vrednostima digitalne humanistike" Lisa Spiro (2012) najpre postavlja pitanje šta je zapravo digitalna humanistika, da li je više određena digitalnošću ili humanistikom, a posebno koliko su duboke promene u humanističkoj paradigmi uslovljene digitalizacijom. Dakle, suprotstavlja novije struje u kojima se insistira na digitalnoj humanistici koja suštinski menja nauku i istraživanja, a ne svodi se na upotrebu kompjutera da "tagira Miltona“, što je očigledno bila površinska izmena u humanistici u njenim početnim digitalnim danima.

Svoj rad Spiro posvećuje vrednostima koje treba da ima zajednica pod nazivom „DH zajednica“ - zajednica digitalne humanistike. Ta zajednica obuhvata ljude iz različitih disciplina, profesija i s različitim teorijskim i metodološkim pristupima. Danas, smatra ona, digitalna humanistika obuhvata humanistička istraživanja i pedagogiju koja je „dublja i eksplicitnija“, „kolaborativnija“ i „transparentnija“ kroz svoje onlajn mreže više nego ikad ranije. Nekad implicitno, a često i eksplicitno ove vrednosti suprotstavlja tradiciji u humanistici kojoj je nedostajala "otvorenost", a obeležavali su je „stari načini mišljenja“, „statičnost“, i sklonost, u socijalnom smislu, ka stvaranju „moćnih klika“. Tako na primer, o vrednostima kojima će se ubuduće upravljati digitalna humanistika, smatra Spiro, neće odlučivati nekakav komitet koji se tajno sastaje, pa dekretom prenosi svoje odluke zajednici, već će one nastajati na „otvoren, participatorski, iterativan, umrežen" način, a dostupan i fleksibilan s obzirom na učešće svih, rekli bismo, „slojeva“: podzajednica različitih tipova, pa, kako kaže: „čak“ i pojedinaca, a kroz: onlajn forume, digitalne konferencije sa neposrednom komunikacijom, blogova. (Spiro, 2012, str.22.)

S obzirom da su osnovne vrednosti humanistike: istraživanje, kritičko mišljenje, debate, pluralizam, potrebno je da se održi ravnoteža između inovacije i tradicije. Ali da bi se to ostvarilo, treba imati na umu da uvek potoji neki ideološki kontekst, te je poželjno da se "senzitivizujemo“ u odnosu na ideološki kontekst tako da ne predstavljamo vrednosti jedne nacije, jedne klase kao univerzalne vrednosti. (Spiro, 2012, str. 18)

Dok $s$ jedne strane postoje oni koji podržavaju tradicionalne hijerarhije, tradicionalno socijalno i kulturno podvajanje, a s pretpostavkom da 
im je publika homogena i univerzalna, koji brane ekspertsko znanje i akademske profesije, naučne autoritete i sl., sada se, s druge strane, ovima suprotstavljaju „anonimni timovi, pluralizam, inovacije, razmene ideja, stvaranje zajednica praksi, izgradnja znanja“. Pa ipak digitalna humanistika treba da „potvrdi i reinterpretira vrednost (tradicije) u vremenu kada se naš odnos prema informacijama, znanju, i kulturnom nasleđu radikalno menja, kada čitavo naše kulturno nasleđe kao ljudske vrste prelazi u digitalnu formu“. I koje su posledice? Dok tradicionalna humanistika vrednuje originalnost, autoritet, i autorstvo, digitalna humanistika promoviše mešanje ideja, otvorenost i mudrost gomile (crowd), zajedničke protokole i kodove". (Spiro, 2012, str. 21)

Kada se pročita ovakav tekst, koji, upravo zato što se bavi pre svega vrednostima kojima treba da teži „digitalna humanistika“, postaje jasno da se pitanje kakav je odnos između tradicionalnih vrednosti humanistike i inovacija koje digitalna humanistika donosi sobom u izvesnoj meri mora sagledati i kao stvar konteksta i vremena. Pogledavši ideološki kontekst, ne može se izbeći primedba da se inovacionoj zajednici pripisuju „otvorenost" koja je verovatno uporediva sa otvaranjem prvih javnih biblioteka „za svakog“ ko je pismen, a uzgred primećujemo da se brzina čitanja i razumevanja teksta nije mogla bitno promeniti u ljudskom rodu, te digitalizacija u tom pogledu teško da može doprineti inoviranju, ma koliko nastojali da uočimo novi „intelekt“; da „statičnost“ koja se pripisuje tradiciji i "fleksibilnost“ digitalnoj humanistici predstavlja takođe epitete koji su relativni, zavisno od toga šta se vrednuje njima; a posebno je interesantno što sada nekako svi mogu da učestvuju, ali se ne eksplicira u čemu to svi mogu da učestvuju, šta tačno svako od tih "svih" doprinosi, itd.

Uostalom, nije prvi put postavljeno pitanje šta neke od tehnoloških novina mogu da donesu kao promenu u našem viđenju sveta, naše kulture, nauke. Baveći se uticajem televizije na američku sredinu tokom druge polovine dvadesetog veka, Neil Postman (1984) kaže da taj novi medij (televizija) ne donosi promene u strukturi ljudskog uma niti u njihovom kognitivnom kapacitetu, već menja javni dikurs, način na koji preznetujemo i primamo informacije.

Tako Postman pominje i ranije tehnološke inovacije: ako kultura koja nema pismenost nije razvila filozofiju, to nije čudno, jer će recimo potenci- 
jalni mislilac iz Čeroki plemena, „dok stigne do drugog aksioma“ ostati bez potrebnih drva za slanje dimnih signala, pa stoga filozofska misao nastaje tek sa razvojem pisma, jer tek tada se može sačuvati misao, tvrdnja, koja će se dalje podvrći proučavanju i kritičkom promišljanju. Pprvi satovi koji mere vreme, stvorili su sredstvo kojima merimo minute i sekunde, sate, i time promenili način na koji gledamo na protok vremena. Prve naočari u dvanaestom veku donele su i ideju da ljudi mogu svoje sposobnosti ili nedostatke poboljšati ili umanjiti. Televizija je spojila sliku i govor, a taj medij ne dopušta oblikovanje političke filozofije, u njemu se kombinuju zabava sa ozbiljnim diskursom. )Postman, 1984, str. 1-14). Svakom od navedenih tehnoloških inovacija može se pridužiti i neka druga: recimo parna lokomotiva ili automobili omogućili su takođe da se komunikacija znatno ubrzan, dok je elektronsko prenošenje poruka promenilo dostupnost i brzinu prenošenja informacija (počev od Morzeovog telegrafa i telefona do današnjeg interneta), te su stvoreni novi sadržaji poput: „vesti dana“ (a danas novine u svojoj digitalnoj formi kombinuju ne samo tekst i sliku, već i video i mogućnost inerakcije, komentara i sl.)

U svakom slučaju, Neil Postman zaključuje da medij u velikoj meri može da odredi sadržaj „javnog diskursa“, jer određuje simboličku formu, izvor informacije, količinu, kontekst u kome se ona prihvata. $U$ tom smislu se digitalna humanistika i kod Postmana i kod Spiro predstavlja eksplicitno kao „prebacivanje čitave kulture u digitalni oblik“, ali i kao promena kulture, jer je svaka reprezentacija kulture uslovljena medijem, a oblikovanje predstave kulture podrazumeva selekciju, perspektivu, tekstualno uobličavanje.

Tradicija i digitalna inovacija u obrazovanju. Digitalna humanistika podrazumeva i inovacije u školstvu, jer se u mnogim kurikulumima u svetu sada pojavljuju termini/pojmovi „medijska pismenost“, „digitalna pismenost", a u tim terminima oseća se, kako kaže D. Berry (2011) dug tradiciji, upravo zbog druge komponente u ovim terminološkim kolokacijama. Međutim, i sama inovacija tog tipa postaje brzo tradicija jer je ponekad teško odrediti ovu vrstu pismenosti - ona, smatra se, podrazumeva stalno učenje s obzirom da se softveri vrlo brzo inoviraju, tako da jednom naučeno ne može večno da traje tokom života pojedinca. Osim toga, nužnost uvođenja digitalne pismenosti nastaje ne samo zato što 
je ona potrebna mladima u budućnosti, već i zato što su oni, kako kaže popularna sintagma "izvorni korisnici" digitalnih medija, te s obzirom na rano upoznavanje sa kompjuterskim igricama, slanjem poruka, socijalnim mrežama i sličnim, vrlo rano postaju upućeni na digitalni tip informacija, te poseduju neku vrstu "tradicionalnog znanja" o njoj.

Međutim, kao uostalom, i čitanje bez digitalizacije, tako i čitanje na internetu podrazumeva viši stepen znanja, onaj koji nas upućuje na veštinu pronalaženja informacija, razumevanja i kritičkog promišljanja, analize i sinteze pročitanog/pronađenog. Tu vrstu podučavanja, smatra se, treba da pruži škola. Ponekad se to suprotstavlja tradicionalnoj pismenosti, gde se insistiralo na evaluaciji i kritičkom promišljanju za koje se "imalo vremena" jer se radilo o štampanom tekstu. Čitanje na internetu svakako podrazumeva više traganja za odgovarajućim materijalom, tehnikama zadavanja ključne reči, postavljanjem pravog pitanja, ponekad za komuniciranjem (kroz razne vizuelne i tekstualne forme) o pročitanom, poznavanje razlitih pretraživača, vikipedija, blogova, mejlova, svega onoga što tehnička pismenost podrazumeva. Pismena osoba mora stalno da uči. Mora se primetiti da neki aspekti prethodno istaknutih "inovacija": sposobnost odvajanju bitnog, ključnog od manje važnog, analiza i sinteza pročitanog, a takođe i potreba za stalnim učenjem, "tokom celog života" predstavljaju novo potenciranje zapravo tradicionalnih vrednosti vezanih za učenje i čitanje, čija se suština nije promenila sa digitalizacijom.

Dalje, vrlo često govori o demokratizaciji, te se stiče utisak da se učenje nastavlja kroz posao, ili opštije rečeno, kroz zajednice prakse, lične i društvene mreže i sl. Međutim ni tradicionalna škola nije nikad bilo jedina sredina u kojima se kultura prenosila. Uvek se učilo i kroz rad, porodicu, socijalne zajednice ili grupe. Čini se da u tekstovima u kojima nalazimo tvrdnje o ovakvim "inovacijama" kao posledici digitalizacije humanistike postoje implicitni popularni stavovi, neutemeljeni na stvarnosti, sa idejom da "ono što se nauči u školi" kasnije samo iskorišćava, a ne dopunjava, da je učenje u porodici, društvenim grupama sporedno. Takva poređenja tradicije i inovacija su zapravo slabo utemeljena na realnim istorijskim faktima.

Uostalom, dobro digitalizovana knjiga nije zanimljivija sama po sebi, primena moderne tehnologije ne čini da gradivo nužno postane zabavno. Digitalizacija je sredstvo, kao što su sve tehnološke inovacije. Tako se u metodici nastave smatralo da magnetofoni i radio aparati revolucionari- 
zuju nastavu, a ispostavilo se da mogu biti samo tehničko pomogalo koje se koristi u relativno malom obimu (bar u odnosu na ono što se mislilo da će postati). Kada digitalizovani rečnici dostupni onlajn većinom modernizovani, na primer, od bilingvalnih postaju multilingvalni, hipertekstovima obogaćeni te dopuštaju dalje traganje za značenjima, ne znači da su suštinski unapređeni. Inovacije pružaju samo ono što je tehnički lako ostvarivo za brzo pronalaženje na recimo, mobilnom telefonu. I čak i ako su onlajn rečnici demokratizovali dostupnost rečnika, te veliki broj vlasnika telefona sada postaju i vlasnici rečnika koje inače ne bi imali u štampanoj formi u svojoj privatnoj biblioteci, nije istraženo dovoljno u kojoj meri a pogotovo ne koliko se oni stvarno i kada, u kakvom kontekstu, koriste u različitim sredinama, a još manje koliko su suštinski promenili način mišljenja o, i kulturološki pristup leksikonu bilo maternjeg bilo stranog jezika.

Neosporno je da se brzina i dostupnost tekstova promenila: pronalaženja tekstova za čitanje koji će unaprediti i podržati učenje je olakšano, integrisanje digitalnih tekstova u kurikulume je već prisutno, pritiskom dugmeta može se ući u kataloge, a biblioteke su dostupne u bilo koje doba dana. Na koji način to stvarno unapređuje znanje i učenje nije sasvim jasno. Čini se da je neka vrsta funkcionalnog raslojavanja nužnost. Mnogi korisnici digitalnih i tradicionalnih tekstova variraju upotrebu dva medija zavisno od ciljeva. Ako su tradicionalni tekstovi narativi, poezija, a digitalni više informativni, reč može biti ne samo o dužini tekstova nego i o svrsi čitanja. Tradicija književnih tekstova koji se uče u školi ili jezičkih vežbanja i učenja u maternjem i stranom jeziku mogu i dalje biti "nezanimljivi" uprkos digitalizaciji i "oživljavanju" materijala raznim digitalnim formama, iz jednostavnog razloga što je sam sadržaj "zastareo" (ono što se zadržalo kao sadržaj potekao iz devetnaestog veka novim generacijama predstavlja davno vreme, a tradicionalno tumačenje jezičke forme i/ili njenog uvežbavanja ne menja se suštinski zbog primene hiperteksta, video slike i zvuka). Inovacije često imaju i specifične funkcije koje ne mogu mehanički inovirati neke tradicionalne elemente kulture.

Socijalni aspekti. Popularna shvatanja su da, dok je u institucionaInom obrazovanju dete ili student deo kolektiva, pred kompjuterom su sami; ili su svi na digitalnim društvenim mrežama, pa se ne viđaju kao 
nekada i tome slično. Drugi pak, potenciraju da digitalizacija doprinosi širenju socijalnih mreža, ističu mogućnost komuniciranja sa ljudima udaljenim iz čitavog sveta. Kada se šalju komentari na blogovima, forumima, tvituje i sl., reagujemo kao pojedinci, samostalno, ali kad dobijamo odgovore, onda komuniciramo i postajemo deo kolektiva.

Ovakva razmišljanja vode se i oko stvaranja kolektivizacije u istraživačkim i akademskim sredinama, gde se ističe da sam priroda medija utiče na povećanje interdisciplinarnosti, kolaborativnosti i pristupačnosti kulture svima. Ističe se činjenica da neposredna interakcija preko videa omogućuju takođe saradnju sa prethodno skoro nezamislivom lakoćom. Sve to uslovljava da se klatno sa slike relativne usamljenosti pred kompjuterom pomera ka sve većoj društvenosti.

U filološkim naukama sve više je prisutna digitalna humanistika, a to najčešće znači statitistička analiza tekstova koji su digitalizovani: književnih dela, jezičkih korpusa, tekstova raznih žanrova. Navodi se često da se digitalna humanistika približava egzaktnijim naukama upravo zbog primene statističke tekstualne analize u proučavanju književnih dela, primene analitičkih digitalnih programa, alatki za analizu teksta, softvera, a to sve se odslikava i u nazivima humanističkih institucija koje se organizuju kao "laboratorije", dok analize jezičkih i književnih tema postaju "eksperimen$t^{\prime \prime}$, ili je ta reč deo naziva u radovima iz digitalne humanistike.

Svedoci smo brojnih posledica takve digitalne reformulacije mnogih tekstova, i nikakako samo u filologiji. Radi se o izveštajima u svim sferama života, popunjavanju formulara koji su tipizirani, "skockani" kako bi se brže pregledali, uredili, pregledali itd. Ali, kako kaže Postman (1984) "danas se istina poistovećuje sa kvantifikacijom, te mnogi iz društvenih nauka jedino priznaju brojke kao istinu i ništa drugo". S obzirom da se radi o promeni u suštini pristupa istraživanjima u humanističkim naukama, istrajnost i dugovečnost te promene može se dovesti u pitanje. Jer, kako kaže ovaj autor "značaj koji se pripisuje bilo kom obliku dosezanja istine zavisi i od medija: ali i druge epsietmološko-medijske metafore, poput: "videti znači verovati", "reći znači verovati", "izračunati znači verovati", "osetiti znači verovati" i sl. izdizali su se ili gubile u značaju u zavisnosti od promena u načinu komunikacije. Kako se kultura od oralne ka pisanoj ka štampanoj ka elektorsnkoj pomerala tako se menjala i ideja o načinu dosezanja istine. Postman, (str. 23-24). 
Digitalna humanistika, dakle, često postavlja pitanja mesta tradicije i inovacije ne samo u istraživačkim oblastima, u kojima je osnovno pitanje promena ontoloških ili epistemoloških postavki, nego i u različitim primenama - u školstvu na primer. lako se već govori da smo danas u post-digitalnoj epohi, suštinska pitanja mesta i odnosa tradicionalnog i inovativnog tek trebaju biti razjašnjenja i istražena pre svega na empirijskoj osnovi. Diskursi koje smo u ovom radu razmatrali pokazuju da su inovacija i obeležja inovativnosti digitalne humanistike dominantni atributi, da ponekad eksplicitno a češće implicitno podrazumevaju tradiciju, ali taj međusobni odnos i vrednovanje tog odnosa može biti i zamagljen nekom vrstom ideološkog pristupa.

\section{Literatura:}

Berry, David M. 2011, The computational turn: thinking about the digital humanities, Culture Machine vol 12.

Berry, David M (2014). Post-digital humanities: computation and cultural critique in the arts and humanities. Educause, 49 (3). pp. 22-26.

Neil Postman, (1985) Amusing Ourselves to Death: Public Discourse in the Age of Show Business New York, Penguin books.

Lisa Spiro, (2012)“This Is Why We Fight": Defining the Values of the Digital Humanities, in: Gold, M.K. (2012). Debates in the digital humanities, pp 16-35.

Gilster, P. (1997) Digital literacy, New York: Wiley \& sons 


\title{
Vesna Polovina \\ University of Belgrade \\ Faculty of Philology
}

\section{TRADITION AND INNOVATION - TWO SIDES \\ OF DIGITAL HUMANITIES}

\begin{abstract}
Summary
In most of the texts and papers in the past few decades dealing with the digital humanities one can find almost always some introductory sentence saying „we live in a new digital age" that has transformed many aspects of our lives. However, it is not always clear what is meant by that: some new creativity or change in practical activity, new creative possibilities in acquiring knowledge and information, or new techniques for spreading already existing knowledge. In digital humanities, and especially in the sciences concerning language, literature and culture, digitalization can be understood as a mere advancement of the already existing culture (e.g. ethnolinguistic reaerch of speech and culture, tagging of the existing classic literature, etc.) or as a new qualitative advancement. And if digitalization of humanities is both quantitative and qualitative advancement, what research questions must be answered? In an effort to answer this we examine tradition and innovation in digital humanities discourses.
\end{abstract}

Key words: tradition, innovation, education, digitalization, humanistic 